\title{
HOMOGENEIDADE DA QUALIDADE FÍSICA DO SOLO NAS ENTRELINHAS DE UM POMAR DE LARANJEIRA COM SISTEMAS DE MANEJO DA VEGETAÇÃO PERMANENTE ${ }^{(1)}$
}

\author{
Jonez Fidalski ${ }^{(2)} \&$ Cássio Antonio Tormena ${ }^{(3)}$
}

\begin{abstract}
RESUMO
A qualidade física do solo é fundamental para a sustentabilidade da produção citrícola. O objetivo deste estudo foi avaliar a homogeneidade da qualidade física do solo nas entrelinhas de um pomar de laranjeira com sistemas de manejo da vegetação permanente. $O$ estudo foi realizado em um experimento com sistemas de manejo de solo nas entrelinhas de um pomar de laranjeira 'Pêra' sobre limoeiro 'Cravo', implantado em 1993 em um Argissolo Vermelho distrófico latossólico, em Alto Paraná, região noroeste do Estado do Paraná. O delineamento experimental utilizado foi de blocos ao acaso com três repetições. Os tratamentos de sistemas de vegetação permanente das entrelinhas foram: gramínea "mato-grosso" ou "batatais" (Paspalum notatum), leguminosa amendoim forrageiro (Arachis pintoi) e o sistema de manejo tradicional com dessecação das plantas espontâneas com herbicida. Em maio de 2003, coletaram-se 216 amostras de solo indeformadas no meio da camada de $0-15 \mathrm{~cm}$ de profundidade e em duas posições de amostragem, no rodado e entrerrodado do trator. As amostras de solo foram usadas para determinar o teor de água em diferentes potenciais matriciais, a densidade do solo, a porosidade total e a resistência do solo à penetração. Também foram calculados a distribuição do tamanho de poros, a capacidade de aeração do solo e o índice S. A inclusão da capacidade de aeração do solo e do índice S associado à distribuição do tamanho de poros permitiu melhor entendimento das alterações físicas resultantes do manejo do solo com vegetações permanentes nas entrelinhas do pomar de laranjeira. O aumento do volume de poros drenados sob a vegetação leguminosa reduz o teor de água do solo, confirmado pela maior capacidade de aeração e pelo índice $\mathrm{S}$ no rodado e entrerrodado. A qualidade física do solo na entrelinha do pomar de laranjeira mantida com gramínea é mais homogênea do que daquele com vegetações espontânea ou leguminosa.
\end{abstract}

Termos de indexação: tamanho de poros, densidade do solo, compactação do solo, manejo do solo, qualidade do solo.

\footnotetext{
(1) Recebido para publicação em setembro de 2006 e aprovado em março de 2007.

(2) Pesquisador da Área de Solos do Instituto Agronômico do Paraná - IAPAR. Caixa Postal 564, CEP $87701-970$ Paranavaí (PR). E-mail: fidalski@iapar.br

(3) Professor do Departamento de Agronomia da Universidade Estadual de Maringá - UEM. Departamento de Agronomia. Av. Colombo 5790, CEP 87020-900 Maringá (PR). Bolsista do CNPq. E-mail: catormena@uem.br
} 


\title{
SUMMARY: HOMOGENEITY OF SOIL PHYSICAL QUALITY IN-BETWEEN ROWS OF AN ORANGE ORCHARD WITH GROUNDCOVER MANAGEMENTSYSTEMS
}

\begin{abstract}
The soil physical quality is fundamental for the sustainability of citrus production. The objective of this study was to evaluate the homogeneity of soil physical quality inbetween the rows of an orange orchard with groundcover management systems. The study was performed in an experimental field with groundcover systems in-between the rows of 'Pêra orange' on 'Rangpur' lime rootstock on a Typic Paleudult, in 1993, in Alto Paraná, in the northwestern region of the state of Paraná, Brazil. An experimental design of random blocks was used, with tree replications. The following groundcover treatments between the rows were studied: bahiagrass (Paspalum notatum), perennial peanut (Arachis pintoi), and the usual management in which weeds of spontaneous vegetation are herbicidecontrolled. In May 2003, 216 undisturbed soil samples were collected from the mid 0-15 cm layer in two sampling positions: under and in-between tractor wheel tracks. Soil samples were used to measure: water content at different matric potentials, soil bulk density, total porosity, and soil penetration resistance. Pore size distribution, air capacity, and $S$ index were also calculated. The inclusion of the soil air capacity and $S$ index associated to pore size distribution broadened the understanding of the soil physical alterations caused by perennial groundcover management types in-between rows of orange orchard. The greater drained pore volume under the leguminous perennial peanut reduces water availability to plants, corroborated by higher air capacity and $S$ index. The physical soil quality in-between rows of orange orchard covered with bahiagrass is more homogeneous that the usual management or perennial peanut.
\end{abstract}

Index terms: pore size distribution, soil bulk density, soil compaction, soil management, soil quality.

\section{INTRODUÇÃO}

A porosidade do solo é constituída por poros de diferentes tamanhos, formas e continuidade, que influenciam a infiltração, o armazenamento e a drenagem da água; o movimento e a distribuição dos gases; e o crescimento das raízes (Kay \& Vandenbygaart, 2002). Em citros, as práticas mecânicas de manejo do solo nas entrelinhas dos pomares de laranjeira apresentam resultados divergentes quanto à modificação em propriedades físicas do solo e ao crescimento de raízes (Carvalho et al., 2001; Bordin et al., 2005). De acordo com Cintra et al. (1983), em solo de textura média, a manutenção da vegetação permanente na entrelinha do pomar de laranjeira reduziu a densidade do solo e aumentou sua porosidade em relação ao manejo da vegetação com gradagem ou herbicida.

A densidade do solo constitui uma das propriedades físicas mais estudadas para a caracterização e identificação dos efeitos dos sistemas de manejo nas condições físicas do solo. A avaliação da distribuição do tamanho ou classes de poros tem permitido identificar ações de manejo entre as posições de amostragem de solo na entrelinha do pomar (Lima et al., 2005; Fidalski et al., 2007). Paralelamente à caracterização da compactação do solo em citros, outras propriedades físicas complementares são avaliadas, como o conteúdo de água e a resistência do solo à penetração (Cintra et al., 1983; Lima et al., 2004, 2005; Santana et al., 2006).

As plantas exigem um sistema poroso com condições para suprir a parte aérea com água, nutrientes e ar e prover-lhes sustentação mecânica. Recentemente, dois indicadores de qualidade física do solo foram propostos por Reynolds et al. (2002) e Dexter (2004). De acordo com os primeiros autores, o solo deveria apresentar valores de 0,34 e 0,66, respectivamente para capacidade de aeração do solo $(\mathrm{ACt} / \mathrm{Pt})$ e armazenamento de água do solo $(\mathrm{CC} / \mathrm{Pt})$, determinados no potencial matricial correspondente à capacidade de campo $(\mathrm{CC})$, no qual $\mathrm{AC}$ é a capacidade de aeração definida pela quantidade de poros drenados a partir do teor de água na saturação e $\mathrm{Pt}$ é a porosidade total do solo. Dexter (2004) propôs o índice $\mathrm{S}$ como indicativo da qualidade física do solo com base na curva de retenção de água, a qual expressa a distribuição de tamanho de poros do solo. O valor do índice $\mathrm{S}$ corresponde à inclinação da curva de retenção no seu ponto de inflexão, e valores do índice S acima de 0,035 são indicativos de boa qualidade física do solo às plantas (Dexter, 2004).

Os índices de qualidade do solo propostos por Reynolds et al. (2002) e Dexter (2004) são independentes da textura do solo, mas há indicações de que apresentam limitações para distinguir os efeitos dos sistemas de manejo de solos pertencentes à classe textural arenosa. Alternativamente, Kay \& Vandenbygaart 
(2002) relataram os bons resultados de estudos que consideraram a porosidade total e a distribuição do tamanho de poros do solo após 15 anos sob sistemas de preparo convencional e direto.

A heterogeneidade da compactação do solo vem sendo verificada por meio de avaliações levando em conta as posições de amostragem de solo na entrelinha (rodado e entrerrodado) de pomares de laranjeiras (Lima et al., 2004; Fidalski et al., 2007), ou exclusivamente linha e entrelinha da cultura (Sanches et al., 1999) associadas aos efeitos da compactação do solo pelo tráfego de máquinas. A heterogeneidade estabelecida pela compactação do solo restringe o crescimento e a atividade das raízes sob as projeções das copas das laranjeiras, reduzindo o volume de solo explorado e aumentando os riscos de estresse hídrico às plantas. A utilização do índice $\mathrm{S}$ poderia contribuir na identificação e caracterização das posições de amostragem de solo, a exemplo do estudo de Tormena \& Silva (2004), os quais constataram melhor condição física para o crescimento e desenvolvimento de culturas anuais na linha do sistema plantio direto e na entrelinha do sistema convencional. Por outro lado, o indicador capacidade de aeração do solo $(\mathrm{ACt} / \mathrm{Pt})$ ainda é pouco utilizado para distinguir a qualidade do solo entre posições de amostragem de solo.

O objetivo deste estudo foi avaliar a homogeneidade da qualidade física do solo nas entrelinhas de um pomar de laranjeira com sistemas de manejo da vegetação permanente.

\section{MATERIAL E MÉTODOS}

O estudo foi realizado em um pomar de laranjeira 'Pêra' [Citrus sinensis (L.) Osb.] sobre limoeiro 'Cravo' Citrus limonia (Osb.), plantado em 1993, na Fazenda São Judas Tadeu, em Alto Paraná, noroeste do Paraná, localizado nas proximidades das coordenadas $23^{\circ} 5^{\prime} \mathrm{S}, 52^{\circ} 26^{\prime} \mathrm{W}$ e altitude de $480 \mathrm{~m}$. O clima na região é subtropical (Cfa), sem estação seca definida e com precipitações anuais de $1.500 \mathrm{~mm}$ (IAPAR, 2000). Para caracterização da classe de solo, foi aberta uma trincheira de $2 \mathrm{~m}$ de profundidade, seguida da coleta de amostras de solos para as análises granulométricas pelo método do hidrômetro de Bouyocus (Embrapa, 1997) e do teor de água retido nos potenciais matriciais de $-80 \mathrm{hPa}$ e $-15.000 \mathrm{hPa}$, respectivamente para a capacidade de campo e o ponto de murcha permanente (Quadro 1). O solo corresponde a um Argissolo Vermelho distrófico latossólico textura arenosa/média A moderado relevo ondulado (Embrapa, 2006), desenvolvido a partir do arenito da Formação Caiuá.

Paralelamente ao plantio das laranjeiras em 1993, nas entrelinhas do pomar foi feito o plantio de estolões da gramínea "grama mato-grosso" ou "grama batatais" Paspalum notatum (Flügge) e a semeadura de sementes da leguminosa amendoim forrageiro Arachis pintoi (Krap. \& Greg.) e o sistema de manejo tradicional com dessecação das plantas espontâneas com herbicida pós-emergente (Glyphosate) a partir de 1996, após o cultivo intercalar de duas linhas de abacaxi desde 1993 (Fidalski et al., 1999). Quando necessário, realizaram-se roçadas mecânicas para manejo da vegetação nas entrelinhas. Essas três vegetações (gramínea, leguminosa e espontânea) constituíram os três tratamentos, dispostos no delineamento experimental de blocos ao acaso com três repetições. As parcelas experimentais apresentavam 15 plantas, com três linhas no espaçamento $7 \times 4 \mathrm{~m}$, com a parcela útil correspondendo às três plantas centrais e duas entrelinhas adjacentes.

Na primeira quinzena de maio de 2003 foi realizada a amostragem do solo sob o tráfego de máquinas e implementos agrícolas e, paralelamente, na área do entrerrodado. Os pontos de amostragem foram referenciados em três transeções perpendiculares aos troncos das três laranjeiras úteis de cada parcela experimental: no rodado $(2,5$ e 4,2 m à esquerda e à direita do tronco das laranjeiras) e entrerrodado (3,2 e $3,5 \mathrm{~m}$ à esquerda e à direita do tronco das laranjeiras). Foram coletadas amostras não-deformadas de solo no meio da camada de $0-15 \mathrm{~cm}$ de profundidade, utilizando anéis metálicos com dimensões de $5 \mathrm{~cm}$ de diâmetro e $5 \mathrm{~cm}$ de altura, totalizando 216 amostras.

Quadro 1. Características granulométricas e teores de água na capacidade de campo (CC) e no ponto de murcha permanente (PMP) dos horizontes do Argissolo Vermelho distrófico latossólico

\begin{tabular}{ccccccc}
\hline Horizonte & Profundidade & Argila & Silte & Areia & CC & PMP \\
\hline & $\mathrm{cm}$ & & $\mathrm{g} \mathrm{kg}^{-1}$ & $\mathrm{~m}^{3} \mathrm{~m}^{-3}-$ & \\
$\mathrm{n}$ & $0-6$ & 90 & 30 & 880 & 0,23 & 0,04 \\
$\mathrm{~A}$ & $7-25$ & 70 & 20 & 910 & 0,23 & 0,04 \\
$\mathrm{Bt}$ & $26-55$ & 180 & 20 & 800 & 0,22 & 0,07 \\
$\mathrm{Bw}$ & $56-200$ & 210 & 20 & 770 & 0,22 & 0,08 \\
\hline
\end{tabular}


Para determinação das curvas de retenção de água do solo, conjuntos de 18 amostras indeformadas de solo (três tratamentos, duas posições de amostragens e três repetições) foram submetidos aos potenciais matriciais

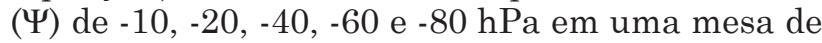
tensão (Romano et al., 2002) e de -100, -300, -500, $-700,-1.000,-4.000$ e $-15.000 \mathrm{hPa}$ em placas porosas (Dane \& Hopmans, 2002). Após atingir o equilíbrio hidráulico, as amostras foram pesadas, e determinouse a resistência do solo à penetração com um penetrômetro estático de laboratório (Tormena et al., 1998). Em seguida, as amostras foram secas em estufa $\mathrm{a} \pm 105{ }^{\circ} \mathrm{C}$ por $24 \mathrm{~h}$, para determinação do teor de água e da densidade do solo (Grossman \& Reinsch, 2002).

Os indicadores capacidade de aeração do solo (ACt/ $\mathrm{Pt}$ ) e capacidade de armazenamento de água do solo (CC/Pt) foram calculados conforme Reynolds et al. (2002), em que CC é o conteúdo de água do solo retido no potencial matricial equivalente à capacidade de campo ( $\Psi=-0,008 \mathrm{MPa}$ ) (Reichardt, 1988) e ACt é a porosidade do solo drenada entre a saturação e o CC. A porosidade total do solo (Pt) foi obtida: [1-(densidade do solo/densidade de partículas do solo)], utilizando-se o valor médio de $2,62 \mathrm{t} \mathrm{m}^{-3}$ para a densidade de partículas do solo, determinado nas 216 amostras de solo.

A distribuição do tamanho de poros foi feita segundo Prevedello (1996), com o diâmetro dos poros calculado pela equação de ascensão capilar: $|\Psi|=[2 \sigma(\cos \Phi) /$ ( $\rho g r)]$; logo: $d=\{[4 \sigma(\cos \Phi)] /(\rho g|\Psi|\}$, em que $|\Psi|$ é o valor em módulo do potencial matricial $(\mathrm{m}) ; \sigma$, a tensão superficial da água a $20^{\circ} \mathrm{C}\left(72,7510^{-3} \mathrm{~N} \mathrm{~m}^{-1}\right) ; \Phi$, o ângulo de contato entre o menisco e a parede do tubo capilar, assumido ser igual a $0 ; r$, o raio do poro $(\mu \mathrm{m})$; $d$, o diâmetro do poro ( $\mu \mathrm{m})$; $g$, a aceleração da gravidade $\left(9,81 \mathrm{~m} \mathrm{~s}^{-2}\right)$; e $\rho$, a densidade ou peso específico da água $\left(1.000 \mathrm{~kg} \mathrm{~m}^{-3}\right)$.

$\mathrm{O}$ cálculo do índice $\mathrm{S}$ foi feito conforme Dexter (2004). As curvas de retenção de água do solo foram ajustadas pelo modelo matemático proposto por van Genuchten (1980): $\theta=\theta \mathrm{r}+\left\{(\theta \mathrm{s}-\theta \mathrm{r}) /\left[1+(\alpha \Psi)^{n}\right]{ }^{m}\right\}$, adotando-se a restrição $[m=1-(1 / n)]$, em que $\Psi$ é o potencial matricial $(\mathrm{cm}) ; \theta$ o conteúdo de água $\left(\mathrm{m}^{3} \mathrm{~m}^{-3}\right)$; $\theta \mathrm{r}$, o conteúdo de água residual $\left(\mathrm{m}^{3} \mathrm{~m}^{-3}\right) ; \theta \mathrm{s}$, o conteúdo de água na saturação $\left(\mathrm{m}^{3} \mathrm{~m}^{-3}\right)$; e $\alpha\left(\mathrm{hPa}^{-1}\right)$ e $n$, coeficientes empíricos do modelo obtidos no ajuste dos dados. $\mathrm{O}$ valor de $\theta$ s correspondeu à porosidade total do solo (Pt). Os coeficientes de regressão do modelo matemático foram obtidos pelo método de GaussNewton com o procedimento NLIN disponível em SAS Institute (2001), utilizando-se os valores médios de três amostras por potencial matricial para cada vegetação e posição de amostragem de solo.

O índice $\mathrm{S}$ foi determinado a partir dos coeficientes das curvas de retenção de água do solo, utilizando-se a equação proposta por Dexter (2004): | $\mathbf{S} \mid=-\mathrm{n}(\theta \mathrm{s}-\theta \mathrm{r})$ $[(2 \mathrm{n}-1) /(\mathrm{n}-1)]^{[(1 / \mathrm{n})-2]}$.

Os dados originais das variáveis volume de poros drenados, densidade do solo, porosidade total, teor de água e resistência do solo à penetração apresentaram distribuição normal dos resíduos pelo teste ShapiroWilk e homocedasticidade das variâncias pelo teste Levene superiores a $10 \%$ (Vieira, 1999). Posteriormente, estas variáveis foram submetidas ao teste de comparação de médias pelo teste de Tukey a $5 \%$, utilizando procedimentos disponibilizados pelo programa estatístico SAS Institute (2001).

\section{RESULTADOS E DISCUSSÃO}

O volume de poros drenados foi dependente do sistema de manejo da vegetação na posição entrerrodado (Figura 1). Sob a vegetação leguminosa verificou-se, estatisticamente, maior volume de poros drenados nos diâmetros de 3 e 49 um no entrerrodado, comparado ao das vegetações gramínea e espontânea, respectivamente. No rodado não houve diferença estatística do volume de poros drenados entre as vegetações, contrariando os resultados obtidos por Lima et al. (2005).

Para o diâmetro de poros drenados de 3 e $49 \mu \mathrm{m}$, o solo sob a vegetação leguminosa reteve, estatisticamente $(\mathrm{p}<0,05)$, menor teor de água no solo na posição entrerrodado (Quadro 2 e Figura 1), comportamento hídrico do solo também verificado por Perin et al. (2000) para essa leguminosa (Arachis pintoi).

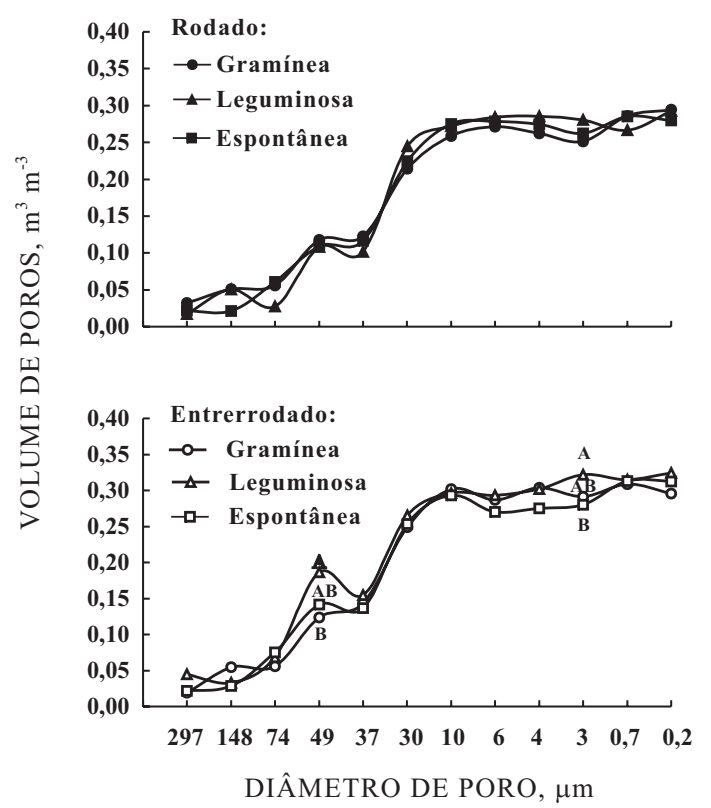

Figura 1. Volume de poros drenados para os diâmetros de poros nas posições de amostragem (rodado e entrerrodado) e vegetações (gramínea, leguminosa e espontânea). Médias seguidas da mesma letra, dentro da mesma posição de amostragem e diâmetro de poro, não diferem entre si pelo teste de Tukey a $5 \%$. 
Verificou-se também menor densidade do solo e maior porosidade total do solo, culminando com a redução da resistência do solo à penetração, mesmo com menor teor de água no solo (Quadro 2). Por outro lado, considerando-se o valor crítico de 2,20 MPa para a produção de citros obtidos por Abercrombie \& Plessis

Quadro 2. Valores médios de densidade do solo, porosidade total, teor de água e resistência do solo à penetração em função do diâmetro de poro drenado nas posições de amostragem (rodado e entrerrodado) e vegetações (gramínea, leguminosa e espontânea)

\begin{tabular}{|c|c|c|c|c|c|c|}
\hline Vegetação & $\begin{array}{c}\text { Posição de } \\
\text { amostragem }\end{array}$ & $\begin{array}{l}\text { Diâmetro de } \\
\text { poro }\end{array}$ & $\begin{array}{l}\text { Densidade do } \\
\text { solo }\end{array}$ & $\begin{array}{l}\text { Porosidade } \\
\text { total }\end{array}$ & $\begin{array}{l}\text { Teor de } \\
\text { água }\end{array}$ & $\begin{array}{c}\text { Resistência } \\
\text { do solo }\end{array}$ \\
\hline & & $\mu \mathrm{m}$ & $\mathrm{Mg} \mathrm{m}^{-3}$ & \multicolumn{2}{|c|}{$\mathrm{m}^{3} \mathrm{~m}^{-3}$} & $\mathrm{MPa}$ \\
\hline Gramínea & rodado & 74 & 1,64 & 0,38 & $0,32 \mathrm{~A}^{(1)}$ & 0,68 \\
\hline Gramínea & rodado & 49 & 1,67 & 0,36 & 0,24 & 1,02 \\
\hline Gramínea & rodado & 37 & 1,67 & 0,36 & 0,24 & 0,90 \\
\hline Gramínea & rodado & 10 & 1,68 & 0,36 & 0,10 & 2,18 \\
\hline Gramínea & rodado & 3 & 1,73 & 0,34 & 0,09 & 4,10 \\
\hline Gramínea & rodado & 0,2 & 1,66 & 0,37 & 0,07 & 3,66 \\
\hline Leguminosa & rodado & 74 & 1,71 & 0,35 & $0,32 \mathrm{~A}$ & 0,84 \\
\hline Leguminosa & rodado & 49 & 1,68 & 0,36 & 0,25 & 1,05 \\
\hline Leguminosa & rodado & 37 & 1,72 & 0,34 & 0,25 & 0,85 \\
\hline Leguminosa & rodado & 10 & 1,71 & 0,34 & 0,07 & 2,89 \\
\hline Leguminosa & rodado & 3 & 1,70 & 0,35 & 0,07 & 3,18 \\
\hline Leguminosa & rodado & 0,2 & 1,71 & 0,35 & 0,06 & 7,27 \\
\hline Espontânea & rodado & 74 & 1,72 & 0,35 & $0,28 \mathrm{~B}$ & 1,00 \\
\hline Espontânea & rodado & 49 & $1,72 \mathrm{a}^{(2)}$ & $0,34 \mathrm{~b}$ & 0,23 & $1,25 \mathrm{a}$ \\
\hline Espontânea & rodado & 37 & 1,73 & 0,34 & 0,24 & 1,04 \\
\hline Espontânea & rodado & 10 & $1,72 \mathrm{a}$ & 0,34 & 0,06 & 3,90 \\
\hline Espontânea & rodado & 3 & 1,73 & 0,34 & 0,08 & 3,63 \\
\hline Espontânea & rodado & 0,2 & $1,74 \mathrm{a}$ & 0,34 & 0,05 & 8,79 \\
\hline Gramínea & entrerrodado & 74 & 1,64 & 0,38 & 0,32 & 0,71 \\
\hline Gramínea & entrerrodado & 49 & 1,63 & 0,38 & $0,25 \mathrm{~A}$ & 0,70 \\
\hline Gramínea & entrerrodado & 37 & 1,64 & 0,37 & 0,23 & 0,74 \\
\hline Gramínea & entrerrodado & 10 & 1,60 & 0,39 & 0,09 & 1,27 \\
\hline Gramínea & entrerrodado & 3 & $1,63 \mathrm{~B}$ & $0,38 \mathrm{~A}$ & $0,09 \mathrm{~A}$ & $2,26 \mathrm{~B}$ \\
\hline Gramínea & entrerrodado & 0,2 & 1,67 & 0,36 & 0,07 & 5,03 \\
\hline Leguminosa & entrerrodado & 74 & 1,67 & 0,36 & 0,29 & 0,68 \\
\hline Leguminosa & entrerrodado & 49 & 1,63 & 0,38 & $0,20 \mathrm{~B}$ & 0,71 \\
\hline Leguminosa & entrerrodado & 37 & 1,65 & 0,37 & 0,22 & 0,56 \\
\hline Leguminosa & entrerrodado & 10 & 1,64 & 0,37 & 0,08 & 1,91 \\
\hline Leguminosa & entrerrodado & 3 & $1,59 \mathrm{~B}$ & $0,39 \mathrm{~A}$ & $0,07 \mathrm{~B}$ & $1,88 \mathrm{~B}$ \\
\hline Leguminosa & entrerrodado & 0,2 & 1,63 & 0,38 & 0,05 & 4,22 \\
\hline Espontânea & entrerrodado & 74 & 1,62 & 0,38 & 0,31 & 0,52 \\
\hline Espontânea & entrerrodado & 49 & $1,64 \mathrm{~b}$ & $0,38 \mathrm{a}$ & $0,23 \mathrm{AB}$ & $0,81 \mathrm{~b}$ \\
\hline Espontânea & entrerrodado & 37 & 1,66 & 0,37 & 0,24 & 0,70 \\
\hline Espontânea & entrerrodado & 10 & $1,65 \mathrm{~b}$ & 0,37 & 0,08 & 1,70 \\
\hline Espontânea & entrerrodado & 3 & $1,72 \mathrm{~A}$ & $0,34 \mathrm{~B}$ & $0,06 \mathrm{~B}$ & $3,89 \mathrm{~A}$ \\
\hline Espontânea & entrerrodado & 0,2 & $1,66 \mathrm{~b}$ & 0,37 & 0,06 & 3,76 \\
\hline
\end{tabular}

(1) Médias seguidas de mesma letra maiúscula, na coluna, na mesma posição de amostragem, não diferem entre si pelo teste de Tukey a $5 \% .{ }^{(2)}$ Médias seguidas de mesma letra minúscula, na coluna, na mesma vegetação, não diferem entre si pelo teste $\mathrm{F}$ a $5 \%$. 
(1995), o solo sob vegetação espontânea manejada com herbicida apresentaria maior restrição para o desenvolvimento das raízes (Quadro 2).

No solo com manejo das vegetações espontânea e gramínea (Paspalum notatum) verificou-se maior volume de poros drenados no entrerrodado que no rodado, respectivamente para os diâmetros de poros de 0,2 e $10 \mu \mathrm{m}$ (Figura 2). Resultados similares foram também verificados por Fidalski et al. (2007). O maior volume de poros drenados correspondente ao diâmetro de poros de $0,2 \mu \mathrm{m}$, no entrerrodado sob o manejo da vegetação espontânea, está associado ao menor valor de densidade do solo (Quadro 2). Contrariamente, no solo coberto com leguminosa houve maior volume de poros drenados para os diâmetros de poros de 37, 49 e $74 \mu \mathrm{m}$. Os sistemas de manejo com uso de gramínea e leguminosa não apresentaram nenhuma propriedade física do solo sob o entrerrodado que justificasse o maior volume de poros drenados para os diâmetros de poros de 10, 37, 49 e $74 \mu \mathrm{m}$ (Quadro 2 e Figura 2). O aumento do volume de poros drenados sob a vegetação leguminosa observados nas figuras 1 e 2 é atribuído à

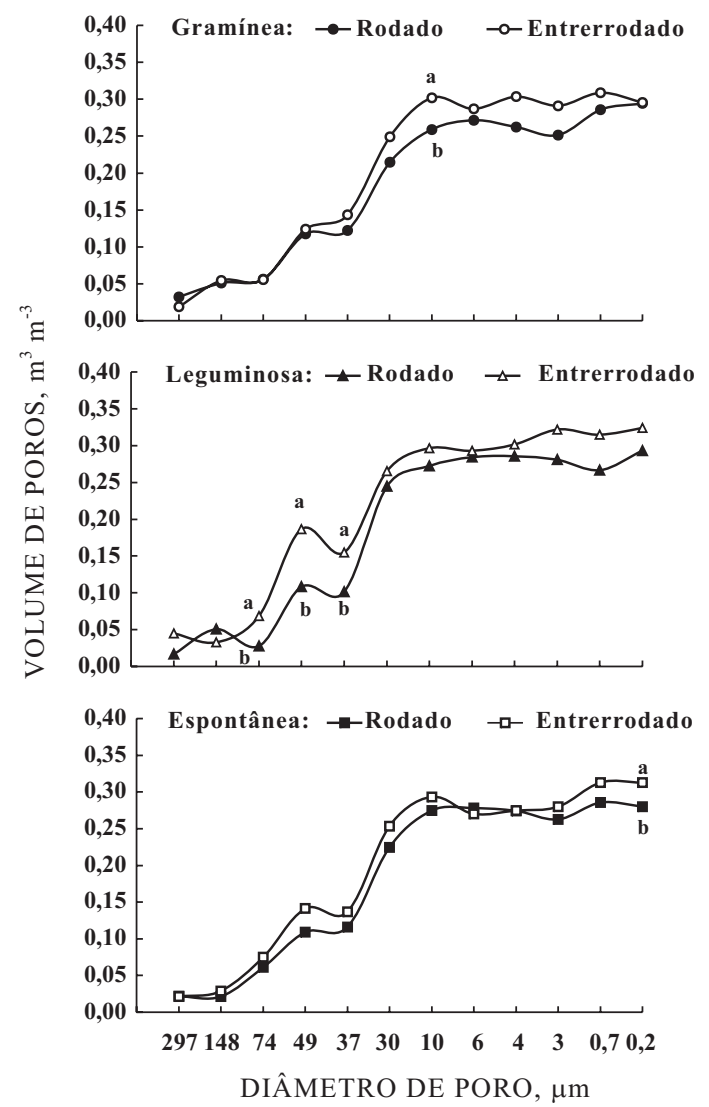

Figura 2. Volume de poros drenados para os diâmetros de poro para as vegetações (gramínea, leguminosa e espontânea) e posições de amostragem (rodado e entrerrodado). Médias seguidas da mesma letra, dentro da mesma vegetação e diâmetro de poro, não diferem entre si pelo teste $\mathrm{F}$ a $5 \%$. formação de poros não-estruturais resultante da decomposição das sementes desta leguminosa, observadas durante a amostragem e por ocasião do tamisamento das amostras de solo. O aumento de poros classificados como microporos (Kiehl, 1979) no solo do entrerrodado sob as vegetações gramínea e espontânea é atribuído à produção de raízes muito finas pelas gramíneas, principalmente o Paspalum notatum, comparado ao Arachis pintoi (Espindola et al., 1998; Perin et al., 2002).

O indicador de capacidade de aeração do solo ACt/ $\mathrm{Pt}$ foi maior no entrerrodado $(0,37-0,42)$ do que no rodado $(0,33-0,36)$ (Figura 3). Adotando o critério de Reynolds et al. (2002), o solo sob a vegetação gramínea apresentou valores médios de ACt/Pt próximos ao valor ideal de 0,33 , que foram observados no rodado e entrerrodado, denotando melhor continuidade da qualidade física do solo em toda a extensão da entrelinha. Os maiores desequilíbrios são observados no solo sob vegetação leguminosa, com maior capacidade de aeração do solo (ACt/Pt) e menor armazenamento de água do solo (CC/Pt), confirmado pelo maior volume de poros drenados (Figuras 1 e 2).

Os valores do índice $\mathrm{S}$ obtidos a partir das curvas de retenção de água do solo (Quadro 3) foram de 0,110,21 no rodado e $0,10-0,17$ no entrerrodado (Figura 3 ), superiores aos valores sugeridos como ideais para o crescimento de raízes das plantas (Dexter, 2004;
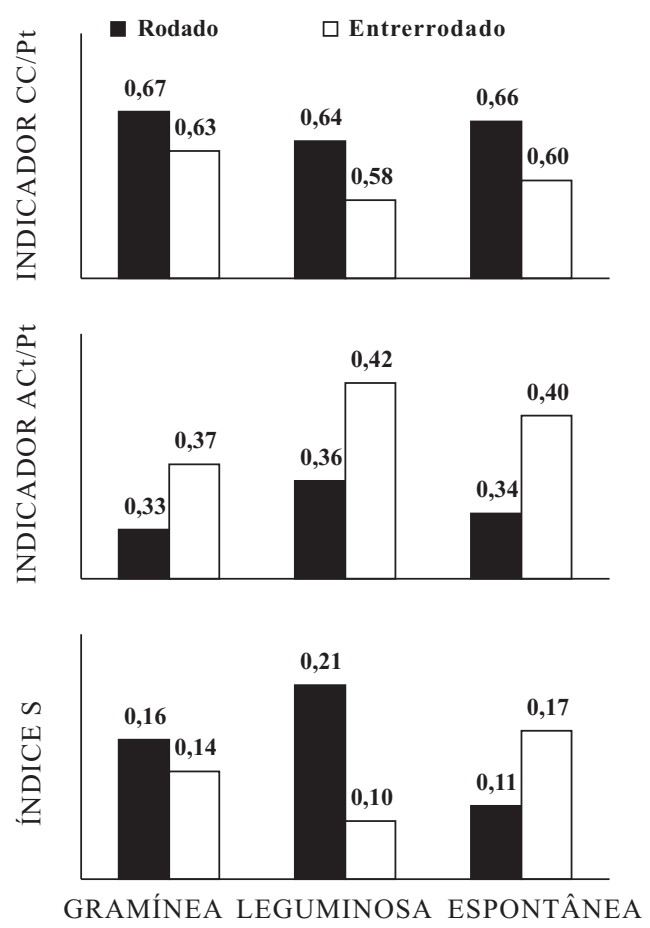

Figura 3. Indicador do armazenamento de água no solo (CC/Pt), indicador da capacidade de aeração do solo ( $\mathrm{ACt} / \mathrm{Pt})$ e índice $\mathrm{S}$ para as posições de amostragem (rodado e entrerrodado) e vegetações (gramínea, leguminosa e espontânea). 
Osuna-Ceja et al., 2006). A superestimativa dos índices $\mathrm{S}$ é atribuída à textura arenosa ( $80 \mathrm{~g} \mathrm{~kg}^{-1}$ de argila), que confere maior inclinação da curva de retenção de água do solo (Quadros 2 e 3), implicando maiores ângulos da tangente no ponto de inflexão. Independentemente dos valores do índice $\mathrm{S}$, verificase, pela distribuição dos seus valores, melhor continuidade horizontal da qualidade do solo sob a vegetação gramínea, confirmada também pela distribuição do tamanho de poros e pelo indicador ACt/ Pt (Figuras 1, 2 e 3).

Os pontos de inflexão das curvas de retenção de água do solo relativos ao índice $\mathrm{S}$ ocorreram em tensões de 67 a $85 \mathrm{~cm}$ e correspondem aos valores extremos sob a vegetação leguminosa, respectivamente, no entrerrodado e rodado (Quadro 2). No solo sob as vegetações gramínea e espontânea, as tensões variaram em torno de $80 \mathrm{~cm}$, equivalentes àquela utilizada para descrever a capacidade de campo deste solo (Fidalski, 2004). Esses resultados, associados aos valores do indicador da distribuição do tamanho de poros (Figura 2) e do indicador $\mathrm{ACt} / \mathrm{Pt}$, determinado na tensão de $80 \mathrm{~cm}$ (Figura 3), equivalente ao diâmetro de poros de $37 \mu \mathrm{m}$, convergem para a maior heterogeneidade horizontal da qualidade da porosidade do solo sob a vegetação leguminosa entre o rodado e o entrerrodado.

Os três indicadores da qualidade física do solo, com base na distribuição do tamanho de poros, $\mathrm{ACt} / \mathrm{Pt}$ e o índice S (Figuras 1, 2 e 3), indicam a melhor qualidade e continuidade física do solo entre o entrerrodado e o rodado sob a vegetação gramínea, comparada às vegetações espontânea e leguminosa. Esses resultados vêm corroborar os estudos de Lima et al. $(2004,2005)$ e Fidalski et al. (2007), ao distinguirem a heterogeneidade horizontal da porosidade do solo nas entrelinhas dos pomares de citros. Os resultados apresentados sugerem que o manejo do solo na entrelinha dos pomares pode contribuir para reduzir o gradiente de qualidade física do solo da linha das plantas em direção ao centro das entrelinhas, ampliando a área de crescimento das raízes e a disponibilidade de água às plantas. Especificamente para os solos com horizontes superficiais enquadrados na classe textural arenosa (teores de argila inferiores a $150 \mathrm{~g} \mathrm{~kg}^{-1}$ ), a manutenção da entrelinha vegetada com a leguminosa (Arachis pintoi) acentuou a drenagem de água do solo, indesejável para o manejo hídrico deste solo por ter comprometido a retenção de água (Quadro 2). Esses resultados coincidem com o comprometimento da taxa de fotossíntese, da condutância estomática e do potencial da água das folhas da laranjeira 'Pêra' em relação às laranjeiras mantidas com as vegetações gramínea e espontânea, atestados no estudo de Fidalski et al. (2006).

Além da melhor continuidade horizontal entre as posições de amostragem de solo nas entrelinhas do pomar, cogita-se que a vegetação gramínea estaria apresentando melhor continuidade vertical de microporos entre o horizonte superficial textura arenosa $(\mathrm{A}$ e $\mathrm{AB})$ e os horizontes subsuperficiais (Bt e $\mathrm{Bw}$ ) do grupamento textural média (Embrapa, 2006), indicado pelo gradiente do teor de água no ponto de murcha permanente (Quadro 1) e confirmado por Fidalski et al. (2007), os quais verificaram maior volume de poros drenados na camada de $20-40 \mathrm{~cm}$ sob o rodado de um pomar de citros com vegetação espontânea.

Considerando que a profundidade efetiva correspondente a $80 \%$ das raízes dos porta-enxertos de citros se encontra nas entrelinhas a $65-68 \mathrm{~cm}$ de profundidade (Neves et al., 2004; Bordin et al., 2005), e pelas correlações significativas entre as distribuições horizontais das raízes dos porta-enxertos de citros nas camadas de 25-50 e 50-75 cm (Neves et al., 2004), o manejo mais apropriado do solo, no presente estudo, seria a manutenção da vegetação permanente com gramínea, para aumentar a retenção de água nos

Quadro 3. Coeficientes das curvas de retenção de água do solo para o modelo van Genuchten $(\theta \mathrm{s}, \mathrm{n}, \alpha, \mathrm{e} \theta \mathrm{r})$, coeficientes de determinação $\left(R^{2}\right)$ e potencial no ponto de inflexão da curva de retenção de água do solo (hi), para os sistemas de manejo (gramínea, espontânea e leguminosa) e posições de amostragem (rodado e entrerrodado)

\begin{tabular}{|c|c|c|c|c|c|c|c|}
\hline Vegetação & Posição de amostragem & $\theta \mathbf{s}$ & $\mathbf{n}$ & $\alpha$ & $\theta \mathbf{r}$ & $\mathbf{R}^{2}$ & hi \\
\hline & & $\mathrm{kg} \mathrm{kg}^{-1}$ & & $\mathrm{hPa}^{-1}$ & $\mathrm{~kg} \mathrm{~kg}^{-1}$ & & $\mathrm{~cm}$ \\
\hline Gramínea & Rodado & 0,1913 & 5,0590 & 0,0132 & 0,0520 & 0,9652 & 79 \\
\hline Gramínea & Entrerrodado & 0,2027 & 3,9333 & 0,0137 & 0,0480 & 0,9930 & 79 \\
\hline Leguminosa & Rodado & 0,1844 & 6,0666 & 0,0121 & 0,0388 & 0,9741 & 85 \\
\hline Leguminosa & Entrerrodado & 0,1983 & 2,8493 & 0,0173 & 0,0393 & 0,9722 & 67 \\
\hline Espontânea & Rodado & 0,1878 & 3,2552 & 0,0140 & 0,0349 & 0,9724 & 80 \\
\hline Espontânea & Entrerrodado & 0,2008 & 4,5643 & 0,0139 & 0,0379 & 0,9727 & 76 \\
\hline
\end{tabular}


diferentes horizontes textura arenosa, assegurando melhores relações hídricas e fisiológicas das laranjeiras, como verificado por Fidalski et al. (2006). A melhoria da qualidade física do solo mantido com gramínea corrobora o estudo de Fidalski et al. (2006) quanto ao não comprometimento da produção de frutos de laranjeira com o manejo da vegetação permanente com gramínea, divergindo de inúmeros estudos da citricultura brasileira (Rodriguez et al., 1964; Dornelles, 1971; Pacheco et al., 1975), que indicam competição por água entre as plantas de cobertura e a cultura de citros.

\section{CONCLUSÕES}

1. A inclusão da capacidade de aeração do solo e do índice S associado à distribuição do tamanho de poros permitiu melhor entendimento das alterações físicas resultantes do manejo do solo com vegetações permanentes nas entrelinhas do pomar de laranja.

2. O aumento do volume de poros drenados sob a vegetação leguminosa reduz o teor de água do solo, o que é confirmado pela maior capacidade de aeração e pelo índice $\mathrm{S}$ no rodado e entrerrodado.

3. A qualidade física do solo na entrelinha do pomar de citros mantida com gramínea é mais homogênea do que com as vegetações espontânea ou leguminosa.

\section{LITERATURA CITADA}

ABERCROMBIE, R.A. \& PLESSIS, S.F.D. The effect of alleviating soil compaction on yield and fruit size in an established Navel orange orchard. J. South. Afr. Soc. Hortic. Sci., 5:85-89, 1995.

BORDIN, I.; NEVES, C.S.V.J.; AIDA, F.T.; SOUZA, W.R.; DAVOGLIO JUNIOR, A.C.; FURLANETO, T.L.R. \& TAVARES FILHO, J. Sistema radicular de plantas cítricas e atributos físicos do solo em um Latossolo argiloso submetido à escarificação. Ci. Rural, 35:820-825, 2005.

CARVALHO, J.E.B.; JORGE, L.A.C.; RAMOS, W.F. \& ARAÚJO, A.M.A. Manejo da cobertura do solo e desenvolvimento do sistema radicular da combinação laranja 'Pêra'/limão 'Cravo' na Bahia e em Sergipe. Laranja, 22:259-269, 2001.

CINTRA, F.L.D.; COELHO, Y.S.; CUNHA SOBRINHO, A.P. \& PASSOS, O.S. Caracterização física do solo submetido a práticas de manejo em pomar de laranja 'Baianinha'. Pesq. Agropec. Bras., 18:173-179, 1983.

DANE, J.H. \& HOPMANS, J.W. Pressure plate extractor. In: DANE, J.H. \& TOPP, C., eds. Methods of soil analysis: Physical methods. Madison, Soil Science Society of America, 2002 v.4. p.688-690.

DEXTER, A.R. Soil physical quality. Part I. Theory, effects of soil texture, density, and organic matter, and effects on root growth. Geoderma, 120:201-214, 2004.
DORNELLES, C.M.M. Manejo de solos em pomares de laranjeiras no Rio Grande do Sul. Sulriograndense, 7:9198, 1971.

EMPRESA BRASILEIRA DE PESQUISA AGROPECUÁRIA EMBRAPA. Manual de métodos de análise de solo. Rio de Janeiro, Centro Nacional de Pesquisa de Solos, 2.ed. 1997. 212p. (Embrapa-CNPS. Documentos, 1)

EMPRESA BRASILEIRA DE PESQUISA AGROPECUÁRIA EMBRAPA. Sistema brasileiro de classificação de solos. 2.ed. Rio de Janeiro, Embrapa Solos, 2006. 306p.

ESPINDOLA, J.A.A.; ALMEIDA, D.L.; GUERRA, J.G.M.; SILVA, E.M.R. \& SOUZA, F.A. Influência da adubação verde na colonização micorrízica e na produção da batatadoce. Pesq. Agropec. Bras., 33:339-347, 1998.

FIDALSKI, J. Propriedades físico-hídricas de um Argissolo Vermelho distrófico latossólico em diferentes sistemas de manejo das entrelinhas de citros. Maringá, Universidade Estadual de Maringá, 2004. 62p. (Tese de Mestrado)

FIDALSKI, J.; MARUR, C.J.; AULER, P.A.M. \& TORMENA, C.A. Produção de laranja com plantas de cobertura permanente na entrelinha. Pesq. Agropec. Bras., 41:927935, 2006.

FIDALSKI, J.; PAVAN, M.A.; AULER, P.A.M. \& JACOMINO, A.P. Produção de frutos de laranjeira Pêra e teores de nutrientes nas folhas e no solo, em Latossolo VermelhoEscuro do noroeste do Paraná. R. Bras. Ci. Solo, 23:273279, 1999.

FIDALSKI, J.; TORMENA, C.A. \& SCAPIM, C.A. Espacialização vertical e horizontal dos indicadores de qualidade para um Latossolo Vermelho cultivado com citros. R. Bras. Ci. Solo, 31:9-19, 2007.

GROSSMAN, R.B. \& REINSCH, T.G. Bulk density and linear extensibility. In: DANE, J.H. \& TOPP, C., eds. Methods of soil analysis: Physical methods. Madison, Soil Science Society of América, 2002. v.4. p.201-228.

INSTITUTO AGRONÔMICO DO PARANÁ - IAPAR. Cartas climáticas do Paraná: edição ano 2000, versão 1.0 . Londrina, 2000. CD-ROM

KAY, B.D. \& VANDENBYGAART, A.J. Conservation tillage and depth stratification of porosity and soil organic matter. Soil Till. Res., 66:107-118, 2002.

KIEHL, E.J. Manual de edafologia. São Paulo, Agronômica Ceres, 1979. 264p.

LIMA, C.L.R.; SILVA, A.P.; IMHOFF, S.; LIMA, H.V. \& LEÃO, T.P. Heterogeneidade da compactação de um Latossolo Vermelho-Amarelo sob pomar de laranja. R. Bras. Ci. Solo, 28:409-414, 2004.

LIMA, H.V.; LIMA, C.L.R.; LEÃO, T.P.; COOPER, M.; SILVA, A.P. \& ROMERO, R.E. Tráfego de máquinas agrícolas e alterações de bioporos em área sob pomar de laranja. R. Bras. Ci. Solo, 29:677-684, 2005.

NEVES, C.S.V.J.; MURATA, I.M.; STENZEL, N.M.C.; MEDINA, C.C.; BORGES, A.V.; OKUMOTO, S.H.; LEE, R.H.C. \& KANAI, H.T. Root distribution of rootstocks for 'Tahiti' lime. Sci. Agric., 61:94-99, 2004. 
OSUNA-CEJA, E.S.; FIGUEROA-SANDOVAL, B.; OLESCHKO, K.; FLORES-DELGADILLO, M.L.; MARTÍNEZ-MENES, M.R. \& GONZÁLES-COSSÍO, F.V. Effecto de la estructura del suelo sobre el desarrollo radical del maíz con dos sistemas de labranza. Agrociencia, 40:27-38, 2006.

PACHECO, E.B.; SILVA, T.C.A.; SANTOS, H.L.; FELDMANN, R.O. \& TEIXEIRA, S.L. Efeito do manejo de um Latossol Vermelho-Amarelo, fase cerrado, sobre o crescimento e produção da laranjeira (Citrus sinensis Osbeck cv. 'Baianinha'). Experimentiae, 19:211-238, 1975.

PERIN, A.; GUERRA, J.G.M. \& TEIXEIRA, M.G. Efeito da morfologia radicular de leguminosas herbáceas perenes na umidade de um Argissolo. Seropédica, Embrapa, 2000 8p. (Embrapa Agrobiologia. Comunicado Técnico, 44)

PERIN, A.; GUERRA, J.G.M.; TEIXEIRA, M.G.; PEREIRA, M.G. \& FONTANA, A. Efeito da cobertura viva com leguminosas herbáceas perenes na agregação de um Argissolo. R. Bras. Ci. Solo, 26:713-720, 2002.

PREVEDELLO, C.L. Física do solo com problemas resolvidos. Curitiba, Saeafs, 1996. 446p.

REICHARDT, K. Capacidade de campo. R. Bras. Ci. Solo, 12:211-216, 1988.

REYNOLDS, W.D.; BOWMAN, B.T.; DRURY, C.F.; TAN, C.S \& LU, X. Indicators of good soil physical quality: Density and storage parameters. Geoderma, 110:131-146, 2002.

RODRIGUEZ, O.; MOREIRA, S. \& ROESSING, C. Estudo de nove práticas de cultivo do solo em pomar cítrico no planalto Paulista. Cruz das Almas, IPEAS, 1964. p.257258 (Boletim Técnico, 2)
ROMANO, N.; HOPMANS, J.W. \& DANE, J.H. Suction table. In: DANE, J.H. \& TOPP, C., eds. Methods of soil analysis: Physical methods. Madison, Soil Science Society of America, 2002. v.4. p.692-698.

SANCHES, A.C.; SILVA, A.P.; TORMENA, C.A. \& RIGOLIN, A.T. Impacto do cultivo de citros em propriedades químicas, densidade do solo e atividade microbiana de um Podzólico Vermelho-Amarelo. R. Bras. Ci. Solo, 23:91-99, 1999.

SANTANA, M.B.; SOUZA, L.S.; SOUZA, L.D. \& FONTES, L.E.F. Atributos físicos do solo e distribuição do sistema radicular de citros como indicadores de horizontes coesos em dois solos de Tabuleiros Costeiros do Estado da Bahia. R. Bras. Ci. Solo, 30:1-12, 2006.

SAS INSTITUTE. SAS/STAT. User's guide. Version 8.2. Cary, NC, 2001. 943p.

TORMENA, C.A. \& SILVA. A.P. Avaliação da qualidade física de um solo utilizando o parâmetro S. In: REUNIÃO BRASILEIRA DE MANEJO E CONSERVAÇÃO DO SOLO E DA ÁGUA, 15., 2004, Santa Maria. Anais. Santa Maria, Sociedade Brasileira de Ciência do Solo, 2004. CDROM

TORMENA, C.A.; SILVA, A.P. \& LIBARDI, P.L. Caracterização do intervalo hídrico ótimo de um Latossolo Roxo sob plantio direto. R. Bras. Ci. Solo, 22:573-581, 1998.

van GENUCHTEN, M.T. A closed-form equation for predicting the hydraulic conductivity of unsaturated soils. Soil Sci. Soc. Am. J., 44:892-898, 1980.

VIEIRA, S. Pressuposições básicas. In: VIEIRA, S. Estatística experimental. 2.ed. São Paulo, Atlas, 1999. p.133-147. 